\title{
Polymerization in Magnetic Field. XIX. Thermal Behavior of the Copoly- mers of Methyl Methacrylate with Glycidyl Methacrylate Synthesized in the Magnetic Field Presence
}

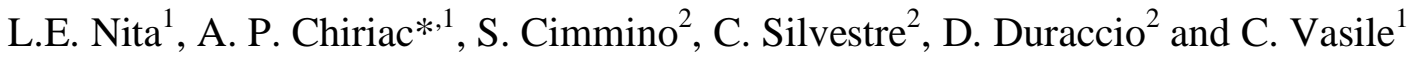 \\ 1 "Petru Poni" Institute of Macromolecular Chemistry, 41 A Grigore Ghica Voda Alley, RO - 700487 Jassy, Romania \\ ${ }^{2}$ Institute of Chemistry and Technology of Polymers, Via Campi Flegrei, 34, 80078 Pozzuoli, Italy
}

\begin{abstract}
The paper evidences changes of thermal properties of poly(methyl methacrylate) as well as methyl methacrylate copolymers with glycidyl methacrylate (GMA) polymers synthesized classic and comparatively in a magnetic field. Samples of poly(methyl methacrylate) and methyl methacrylate copolymers with different amounts of GMA synthesized by radical emulsion polymerization with or without the presence of a continuous electro- magnetic field, they were thus compared. The thermal behavior was studied by Differential Scanning Calorimetry (DSC) and Thermogravimetry (TGA). The paper evidences the higher $\mathrm{T}_{\mathrm{g}}$ as well as the higher thermal stability of the macromolecular chains structures synthesized in the presence of the electromagnetic field.
\end{abstract}

\section{INTRODUCTION}

The interest in the investigation of chemical reactions in magnetic field (MF) has grown in recent years [1-3]. The magnetic field effects (MFEs) were registered in the emulsion polymerization of styrene photoinitiated by dibenzyl ketone $[4,5]$. Application of a moderate MF of 50-1000 G significantly accelerated the polymerization and resulted in an increase of the molecular weight of polystyrene obtained in the emulsion polymerization, due to the MFE attributed to a hyperfine mechanism $[4,5]$.

The copolymers containing glycidyl methacrylate (GMA) have received a special attention owing to their versatile applications such us for obtaining powder coating with better toughness, gloss and durability [6,7]. The copolymerization of methyl methacrylate (MMA) with GMA has been studied previously and the reactivity ratios for this monomer pair have been also reported [8-10]. Their reactivity ratios are relatively close $\left(r_{1}(\mathrm{GMA})=0.700 \pm 0.001\right.$ and $r_{1}(\mathrm{MMA})=$ $0.830 \pm 0.002$ [10]), therefore we will consider similar behavior during reaction process in MF for both comonomers. Thermal behavior of PMMA and of MMA copolymers with GMA was also studied [10]. Piracha and Zulfiqar [11] studied the copolymers of MMA and GMA, with widely differing compositions, synthesized by bulk polymerization by using thermal volatilization analysis, thermogravimetry, differential thermal analysis and pyrolysis-mass spectrometry techniques. The apparent activation energies for the decomposition of the copolymers were calculated from the results of thermogravimetric experiments.

The condensable volatile degradation products have been identified after separation by sub ambient. Non-condensable products of degradation formed during thermogravimetric

*Address correspondence to this author at the "Petru Poni" Institute of Macromolecular Chemistry, 41 A Grigore Ghica Voda Alley, RO - 700487 Jassy, Romania; E-mail: achiriac@icmpp.ro analysis (TGA), were identified using a mass spectrometer attached to the TGA apparatus. They concluded that the presence of the second monomer (GMA) favors combination reactions rather than disproportionation as termination step. Thus, the copolymers degradation occurs only at high temperatures at which the polymers that have no terminal unsaturation degrade. This involves random scission followed by depropagation.

In our previous papers [12-14] it was presented a comparative study regarding the magnetic field effects upon copolymerization process between methyl methacrylate and glycidyl methacrylate using the procedure of radical emulsion polymerization. It has been established that the magnetic field affects both kinetic parameters of the synthesis as well as some of the characteristics of the macromolecular compounds [14].

In the present paper it is presented the effect of the MF upon thermal behavior of poly(methyl methacrylate) and methyl methacrylate copolymers with different amounts of GMA synthesized by radical emulsion polymerization with or without the presence of the field.

\section{EXPERIMENTAL PART}

\section{Materials}

The monomers methyl methacrylate (MMA) (c > $99 \mathrm{wt}$ $\%$, Merck), glycidyl methacrylate (GMA) (c > 97 wt \%, Fluka) were freshly distilled before use.

Sodium lauryl sulfate $\left(\mathrm{C}_{12} \mathrm{H}_{25} \mathrm{O}_{4} \mathrm{SNa}\right)$ - (SLS) from Sigma (c > 95 wt $\%$, )) without further purification was used as tensioactive agent.

Potassium persulphate $\left(\mathrm{K}_{2} \mathrm{~S}_{2} \mathrm{O}_{8}\right)$ - (KPS) was twice recrystallized from twice distilled water.

In all experiments the twice distilled water, which contained no foreign ions, was used. 


\section{Polymerization Process}

MMA copolymers with two different compositions of GMA (3 wt \%, and $25 \mathrm{wt} \%$ ) were prepared by emulsion polymerization of appropriate mixture of monomers at $70^{\circ} \mathrm{C}$, with 0.8 wt \% KPS and 3 wt \% SLS respectively, in magnetic field (MF) and classical way (CW).

The polymerization reaction in the continuous electromagnetic field of $1500 \mathrm{G}$ was made in the same conditions with classical variant: similar vessel shape and geometry, and the same reaction parameters and type of stirring. The emulsion polymerization process developed by classic way $(\mathrm{CW})$ and in the presence of the magnetic field (MF) was described in detail in previous papers [12,13].

The prepared polymeric samples were precipitated in methanol, purified by reprecipitation in methanol from acetone solution, dried under vacuum at room temperature for 48 hours and stored in desiccators.

The molecular structures was appreciated via the bands' identification of the FTIR spectra (on a DIGILAB, Scimitar Series, USA, spectrophotometer, the resolution recording was $4 \mathrm{~cm}^{-1}$; sample concentration $3 \mathrm{mg}$ in $500 \mathrm{mg} \mathrm{KCl} \mathrm{tab-}$ let). The composition of each copolymer was determined from NMR data.

DSC curves were recorded with a heat flow Mettler Toledo DSC-822 under inert atmosphere of nitrogen. The following procedure of heating/cooling was used:

The first cooling: the samples were cooled from 25 to $-70^{\circ} \mathrm{C}$ at a heating rate of $20^{\circ} \mathrm{C} / \mathrm{min}$; kept at $-70^{\circ} \mathrm{C}$ for $1 \mathrm{~min}$.
- $\quad$ I RUN: one sample was heated from -70 to $150^{\circ} \mathrm{C}$; with a heating rate of $20^{\circ} \mathrm{C} / \mathrm{min}$ kept at $150^{\circ} \mathrm{C}$ for $1 \mathrm{~min}$;

- The second cooling: the samples were cooled at $50^{\circ} \mathrm{C} / \mathrm{min}$ to $-70^{\circ} \mathrm{C}$ and kept for $1 \mathrm{~min}$.

- $\quad$ II RUN: the samples were finally heated to $150^{\circ} \mathrm{C}$ at $20^{\circ} \mathrm{C} / \mathrm{min}$.

The $\mathrm{Tg}$ values are determined at the inflection point on the thermo-analytical curves.

Thermo-gravimetric analysis was also performed in nitrogen atmosphere in a temperature range from $30^{\circ} \mathrm{C}$ to $700^{\circ} \mathrm{C}$ by means of TGA/DTA 851 Mettler. Two heating rates were used: 5 and $20 \mathrm{C}^{\circ} / \mathrm{min}$. Two recordings were performed for each sample.

\section{RESULTS AND DISCUSSION}

Table 1 presents the characteristic bands from FT-IR spectra and composition of the copolymers synthesized by classical and in MF ways.

Spectroscopic characterization (Table 1) confirms the presence of both comonomers in copolymers structure in amounts close to those employed in reaction feed. As it is expected, the GMA corresponding bands - at $1600 \mathrm{~cm}^{-1}$ and 2800-3100 $\mathrm{cm}^{-1}$ - increase with the enhance of GMA content. Some indications about structural differences in the copolymers synthesized in MF presence in respect with those prepared by $\mathrm{CW}$ are also underlined. Thus, several bands show higher intensities $\left(1600 \mathrm{~cm}^{-1}, 1690-1760 \mathrm{~cm}^{-1}, 1080\right.$ and $\left.1300 \mathrm{~cm}^{-1}, 2800-3100 \mathrm{~cm}^{-1}\right)$. The intensities of the vibration oscillation absorption corresponding to the polymers

Table 1. Spectral Data of the PMMA and MMA-GMA Copolymers Synthesized without and in MF Presence

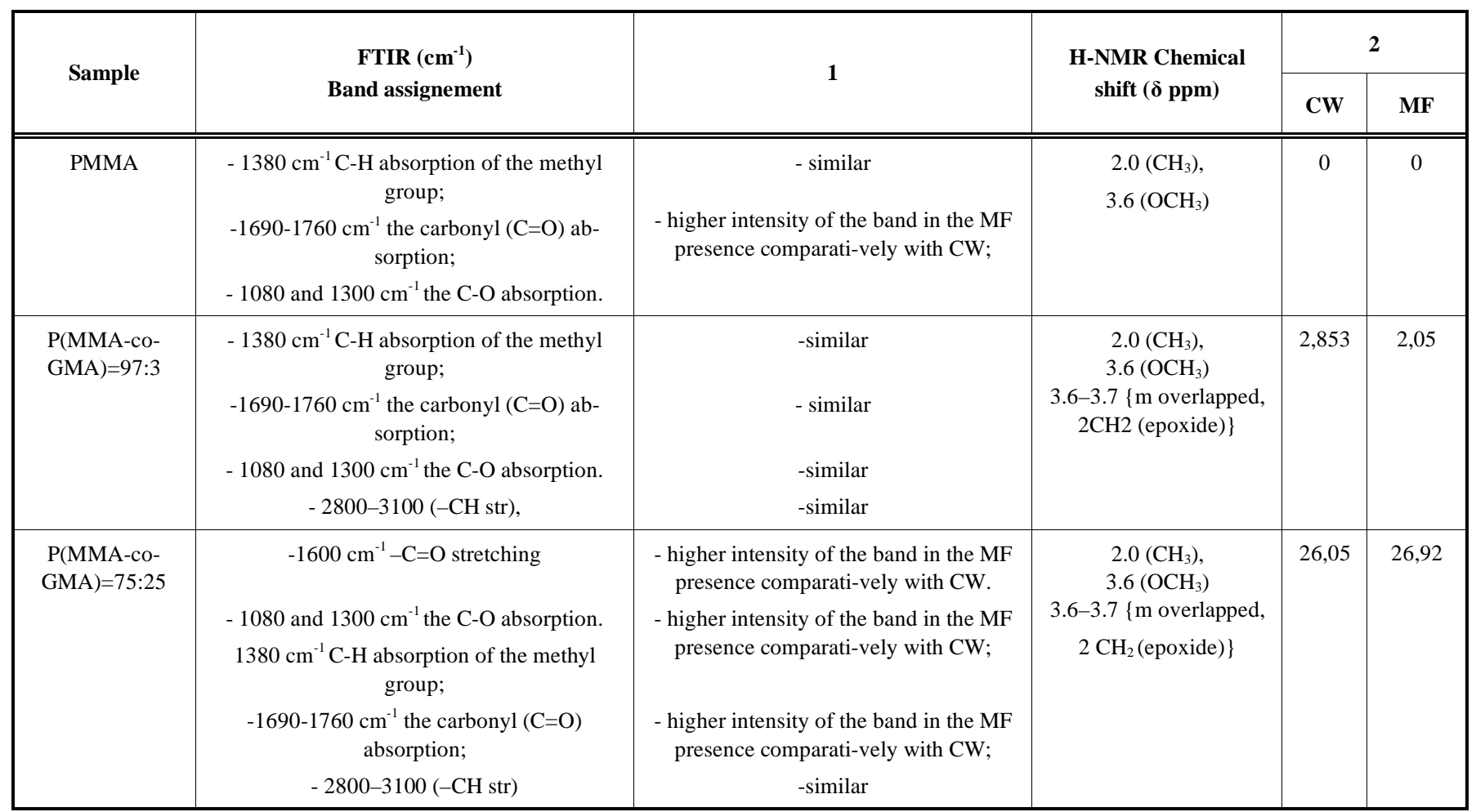

1 - Differences observed in spectra of compounds obtained in MF presence.

2 - GMA in copolymer \% determined from NMR spectra. 
synthesised in the field are attributed to the modification of the strength constant introduced by the inductive and electromeric effects appearing supplementary in the polymeric structures prepared in the field conditions.

The DSC thermo-analytical curves of samples prepared by classic way and in magnetic field respectively are given in Figs. (1 and 2). A transition (glass transition) is observed in all curves in the first and second run. The temperature corresponding to the inflection point of the transition depends on the synthesis conditions and copolymer compositions (Table 2).

\section{RUN}

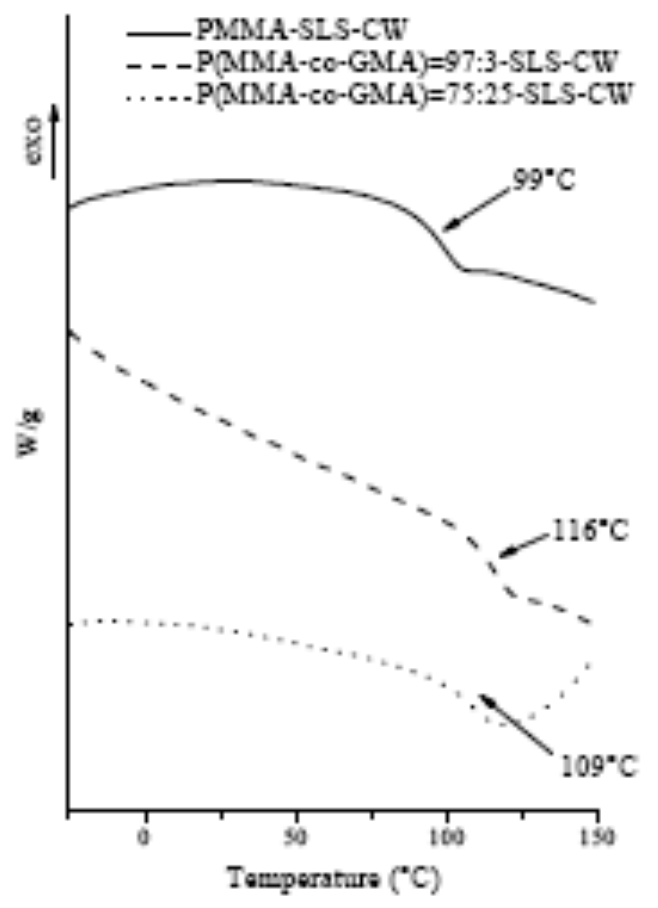

Fig. (1). The DSC curves of the samples synthesized by classical way.

In the first run (not shown) a small endothermic peak was evidenced at about $70-75^{\circ} \mathrm{C}$ for all 3 polymeric samples. This peak does not appear in the second run. Fig. (1) corresponds to second run. Here transition corresponding to $\mathrm{Tg}$ is

\section{IIRUN}

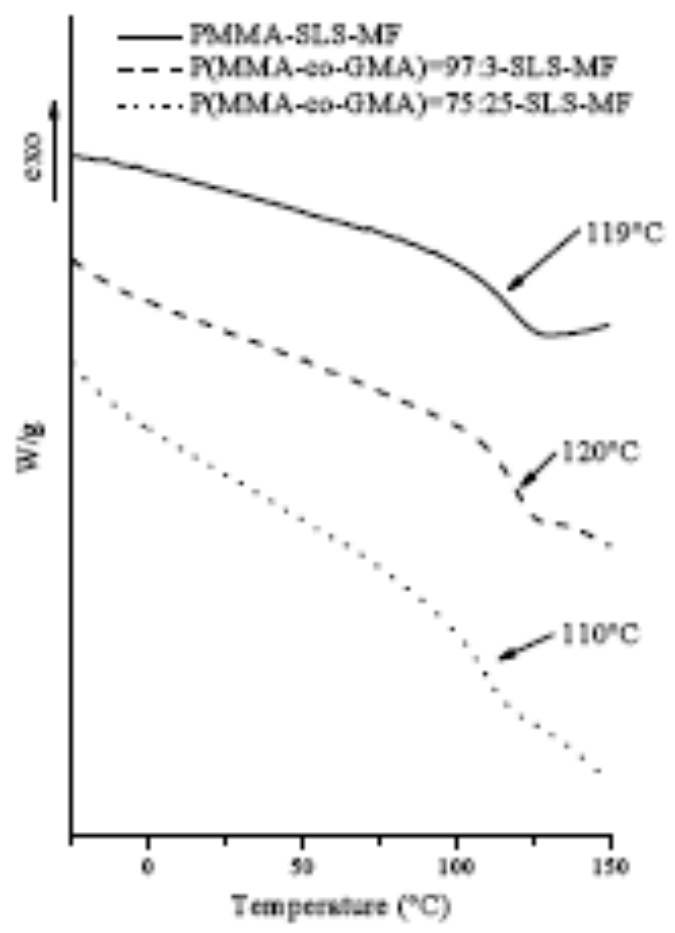

Fig. (2). The DSC curves of the samples synthesized by MF way.

more evident. For PMMA-SLS-CW, Tg was found at $99^{\circ} \mathrm{C}$; adding $3 \mathrm{wt} \%$ of GMA causes the increase up to $116^{\circ} \mathrm{C}$ and the value decreases to $109^{\circ} \mathrm{C}$ when GMA is $25 \%$ (Table 2). If we compare the values of I run and II run, it is evident that the values are similar with the exception of PMMA-SLS$\mathrm{CW}$. This sample has the obtained values placed in the interval $95-108^{\circ} \mathrm{C}$ which was also given in literature [15]. The samples synthesized in MF exhibit well evident transition temperatures at 119,120 and $110^{\circ} \mathrm{C}$ for PMMA, P(MMAco-GMA) $=97: 3$, and P(MMA-co-GMA $)=75: 25$, respectively. Again the sample with highest GMA content shows a Tg at $110^{\circ} \mathrm{C}$, lowered than for PMMA-SLS (Table 2).

If we compare the $\mathrm{CW}$ sample with those prepared in $\mathrm{MF}$ (Fig. 1 and 2) it can be observed that the MF induces an increase of the $\mathrm{Tg}$ values, especially in case of PMMA $\left(99^{\circ} \mathrm{C}\right.$

Table 2a. Tg, the Onset Temperature $\left(T_{i}\right)$ and the Temperature of the Maxima of the Peak $\left(T_{\max }\right)$ for Samples Synthesized in $C W$ and in MF Presence

\begin{tabular}{|c|c|c|c|c|c|}
\hline \multirow{2}{*}{ Samples } & \multirow{2}{*}{ T $_{\mathrm{g}}$ II RUN $\left({ }^{\circ} \mathrm{C}\right)$} & \multicolumn{2}{|c|}{ First peak } & \multicolumn{2}{|c|}{ Second (main) peak } \\
\hline & & $\mathrm{T}_{\mathrm{i}} \mathrm{HR} 20^{\circ} \mathrm{C} / \mathrm{min}$ & T $_{\text {MAX }} H R 20^{\circ} \mathrm{C} / \min$ & $\mathrm{T}_{\mathrm{i}} \mathrm{HR} 20^{\circ} \mathrm{C} / \mathrm{min}$ & $\mathrm{T}_{\text {MAX }} \mathrm{HR} 20^{\circ} \mathrm{C} / \mathrm{min}$ \\
\hline PMMA- MF & 119 & 248 & 280 & 342 & 414 \\
\hline $\mathrm{P}(\mathrm{MMA}-\mathrm{co}-\mathrm{GMA})=97: 3-\mathrm{CW}$ & 116 & - & - & 328 & 402 \\
\hline $\mathrm{P}(\mathrm{MMA}-\mathrm{co}-\mathrm{GMA})=75: 25-\mathrm{CW}$ & 110 & - & - & 345 & 403 \\
\hline $\mathrm{P}(\mathrm{MMA}-\mathrm{co}-\mathrm{GMA})=75: 25-\mathrm{MF}$ & 109 & 270 & 315 & 350 & 411 \\
\hline
\end{tabular}




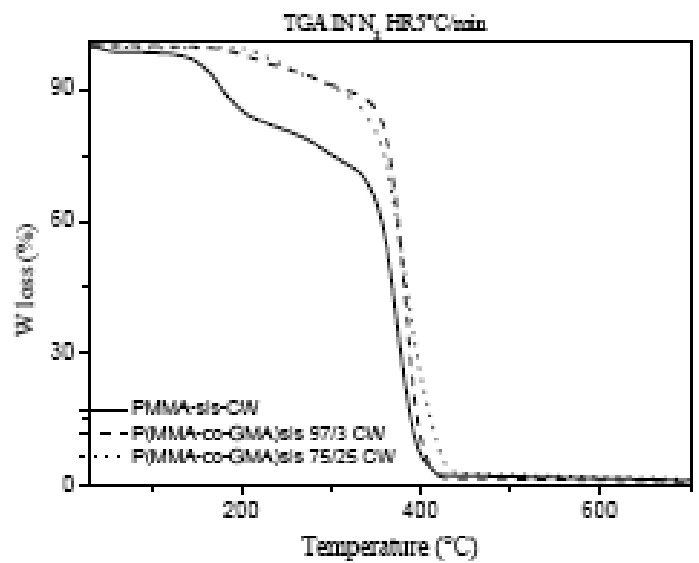

(a)

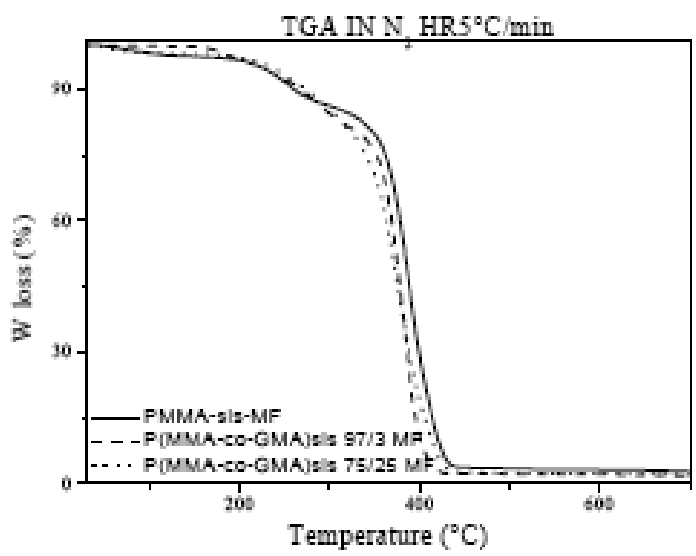

(b)

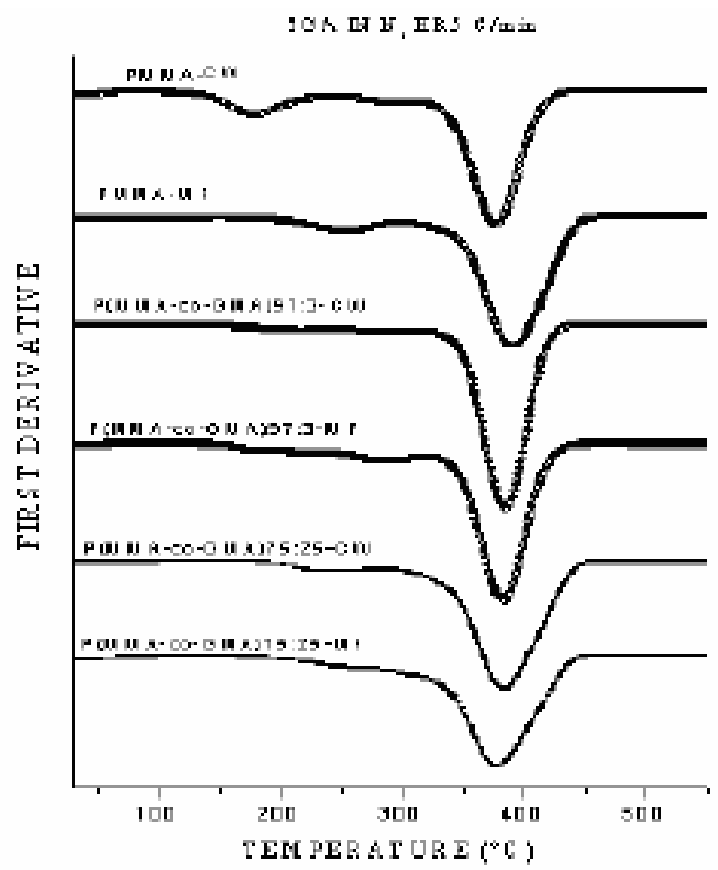

(c)

Fig. (3). TGA curves for PMMA and GMA/MMA copolymers polymerized by CW (a), in MF presence (b) and DTG curves of all samples studied (c) (dynamic atmosphere of nitrogen $5{ }^{\circ} \mathrm{C} / \mathrm{min}$ ).

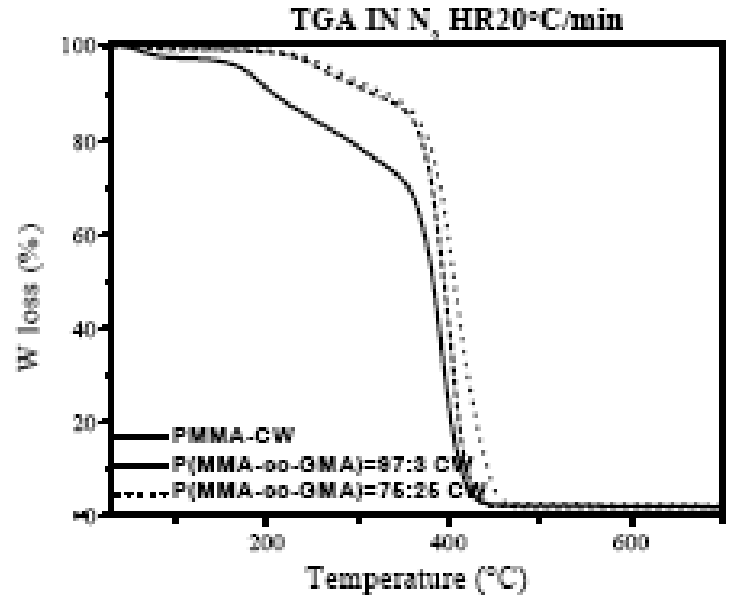

(a)

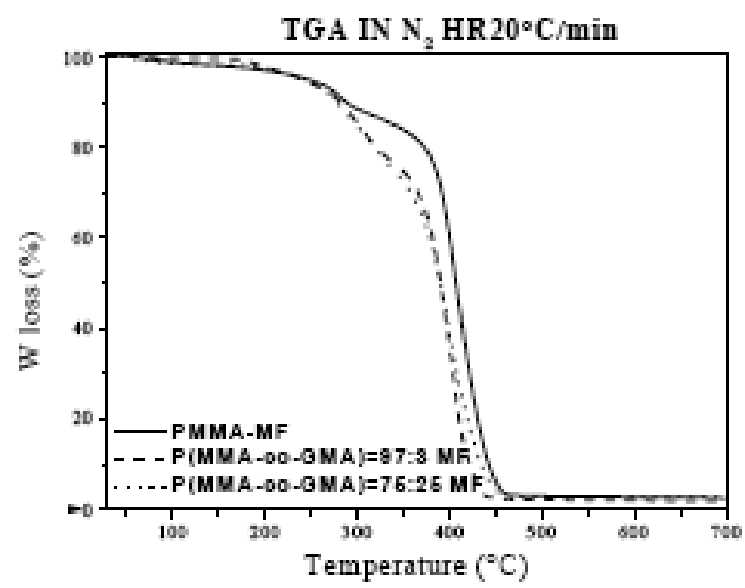

(b)

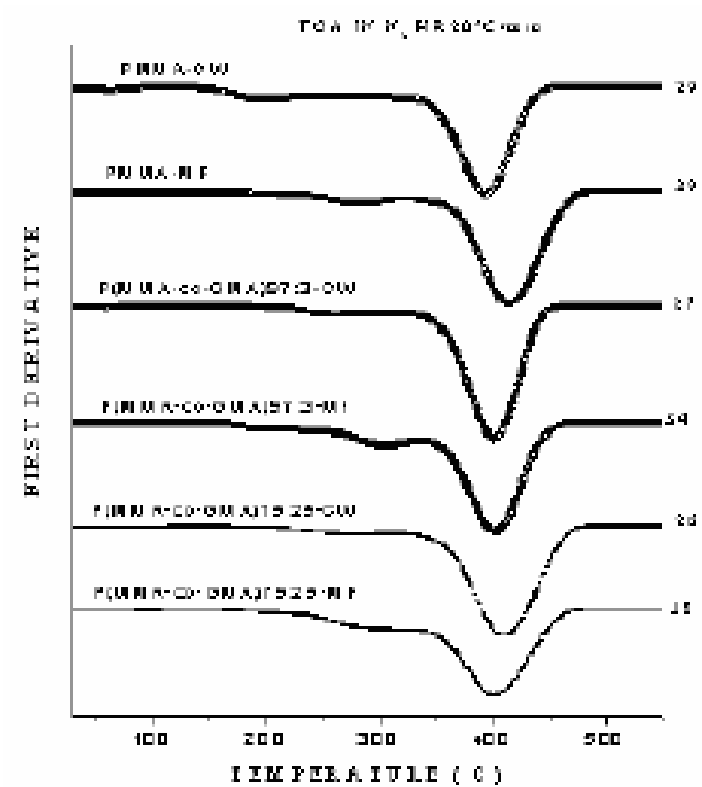

(c)

Fig. (4). TGA curves for PMMA and GMA/MMA copolymers polymerized by CW (a), in MF presence (b) and DTG curves of all samples studied (c) (dynamic atmosphere of nitrogen $20^{\circ} \mathrm{C} / \mathrm{min}$ ). 
Table 2b. The Characteristic Temperature of Decomposition of the Samples CW Synthesized and in MF Presence

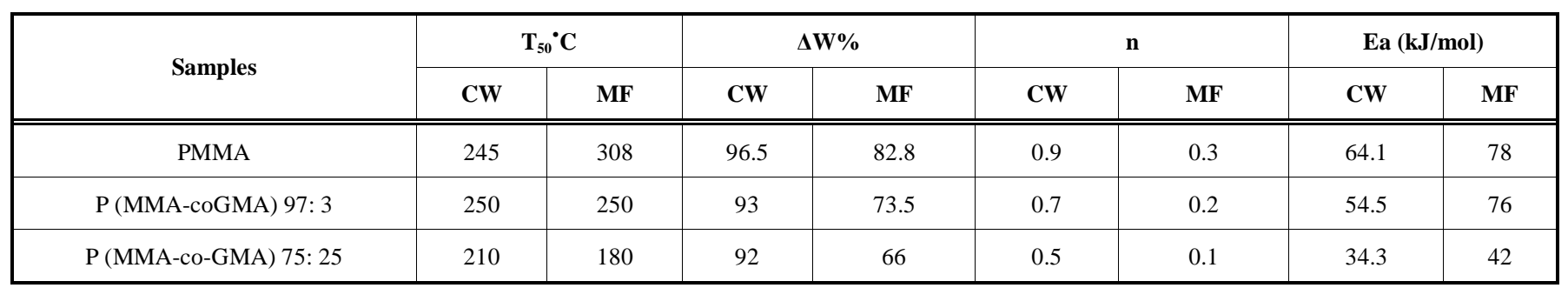

$\Delta \mathrm{w}$ - weight loss at final of the process.

$\mathrm{T}_{50^{-}}$temperature corresponding to $50 \mathrm{wt} \%$ weight loss.

n- reaction order.

Ea - global activation energy

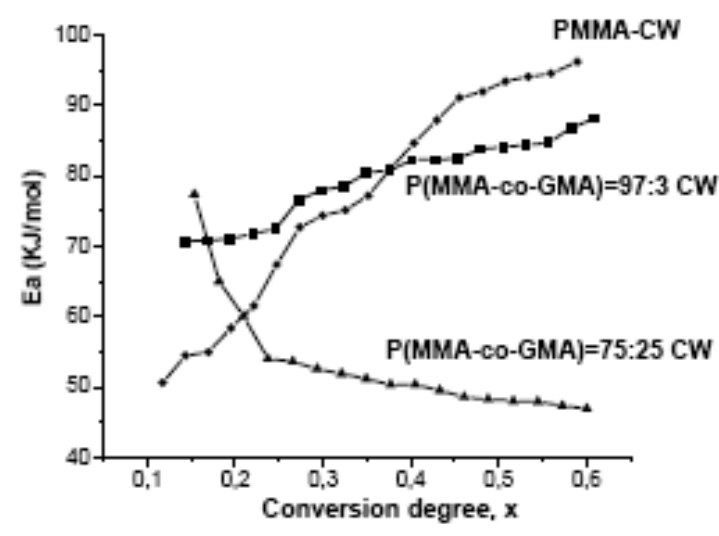

(a)

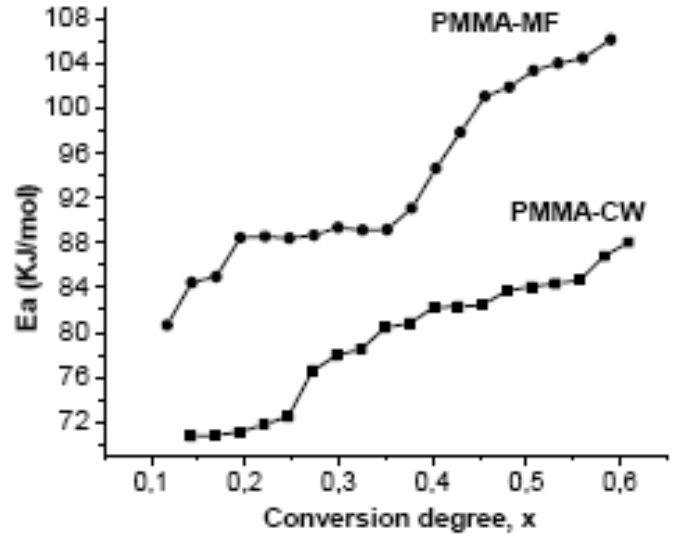

(b)

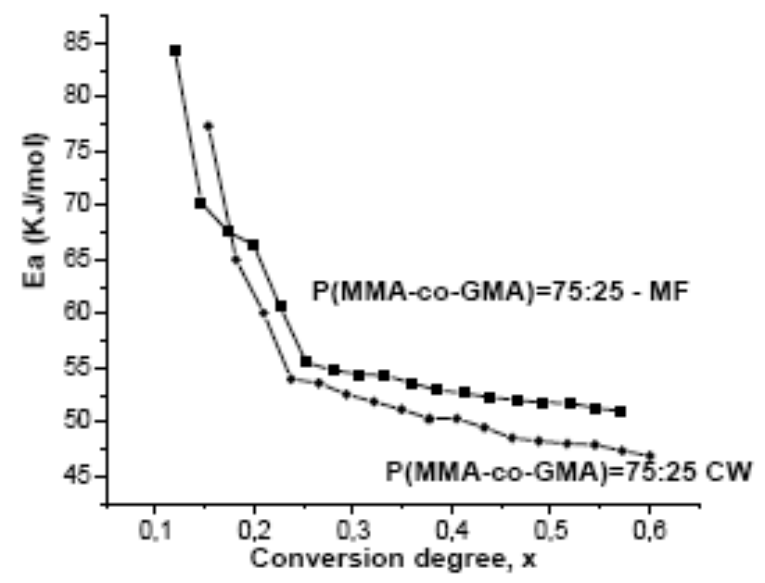

(c)

Fig. (5). Activation energy of the samples.

$\mathrm{CW}$ in respect with $119^{\circ} \mathrm{C}-\mathrm{MF}$ Table 2 ). The increase of $\mathrm{Tg}$ values are explained by morphological changes of the samples synthesized in MF presence being attributed to the catalytic effect of the field on the molecules that can be reshaped through growing of distance interactions and modification of angles between bonds. Studies are in progress to confirm this hypothesis. Table 2 reports also the onset temperature $\left(\mathrm{T}_{\mathrm{i}}\right)$ and temperature of the maxima of the peak corresponding to the first derivative $\left(\mathrm{T}_{\max }\right)$ from the TGA/DTG curves. The maximum fits to the main inflection point of the curves. There is a difference between thermal behavior of the samples prepared in MF presence comparable with those CW prepared - Figs. (3 and 4) and data from Table 2 -. For all samples from the former category an additional thermogravimetric step appears at temperature ranging from $248^{\circ} \mathrm{C}$ to $270{ }^{\circ} \mathrm{C}$ with maximum temperature of weight loss of 280 $315^{\circ} \mathrm{C}$. The weight loss varies between $11.6 \% \mathrm{wt}$ for PMMA -MF to $13.8 \mathrm{wt} \%$ and $19.8 \mathrm{wt} \%$ for copolymers with $3 \%$ and $25 \%$ GMA content respectively. Generally thermal characteristics corresponding to the samples polymerized in MF are superior of those polymerized by CW. PMMA has the best 
thermal stability when it is synthesized in the presence of magnetic field.

This behavior is also confirmed by the variation of the activation energy with conversion degree which was determined using the Reich-Levi method and Coats equation based on the weight loss during the thermo-oxidative process $[16,17,18]$. The evolution of the activation energy values correlated with the GMA content is presented in Fig. (5) and Table 2b. At a given MMA/GMA ratio, growth of the GMA content determines the decrease of the activation energy. At the same time the MF presence determines an increase of the global activation energy Ea (Fig. 5b, c).

The influence of the MF on the thermal behavior is explained on the pre-ordering-structure of the copolymers as a result of the magnetic field presence during syntheses [19, 20].

\section{CONCLUSIONS}

PMMA as well as MMA copolymers with a monomer bearing functional groups - 2,3 epoxy propyl methacrylate have been obtained by classical and in magnetic field polymerization process. It has been established that the presence of the magnetic field during emulsion polymerization of methyl methacrylate and methyl methacrylate copolymerization with GMA leads to the homo- and copolymers exhibiting higher glass transition temperatures and complex thermal stabilities. The increase of $\mathrm{Tg}$ values are explained by morphological changes of polymers synthesized in MF presences, being attributed to the catalytic effect of the field on the molecules that can be re-shaped through growing of distance interactions and modification of angles between bonds as well as to the modification of the strength constant introduced by the inductive and electromeric effects appearing supplementary in the polymeric structures prepared in the field conditions.

Structural and morphological studies are in progress to confirm this hypothesis.

\section{REFERENCES}

[1] Khudyakov, I. V.; Arsu, N.; Jockusch, S.; Turro, N. J. Magnetic and spin effects in the photoinitiation of polymerization. Des. Monom. Polym., 2003, 6 (1), 91-101.

[2] Steiner, U.E.; Ulrich, T. Magnetic field effects in chemical kinetics and related phenomena. Chem. Rev., 1989, 89, 51-147.
[3] Steiner, U.E.; Wolff, H.J. Photochemistry and Photophysics, CRC Press, Boca Raton, Boston 1991.

[4] Turro, N. J.; Chow, M.-F.; Chung, C.-J.; Tung, C.-H. An efficient, high conversion photoinduced emulsion polymerization. magnetic field effects on polymerization efficiency and polymer molecular weight. J. Am. Chem. Soc., 1980, 102, 7391-7395.

[5] Turro, N. J.; Chow, M.-F.; Chung, C.-J.; Tung, C.-H. Magnetic field and magnetic isotope effects on photoinduced emulsion polymerization. J. Am. Chem. Soc., 1983, 105, 1572-1576.

[6] Nishikubo, T.; Saita, S.; Fujii, T. New thermo-crosslinking reactions of polymers containing pendant epoxide groups with various polyfunctional active esters. J. Polym. Sci. Part A, 1987, 25 (5), $1339-1351$.

[7] Ahmad, S.; Zulfiqar, S. Synthesis, characterization and thermal degradation of glycidyl methacrylate- $\alpha$-methyl styrene copolymers. Polym. Degrad. Stab., 2002, 76, 173-177.

[8] Iwakura, Y.; Kurosaki, T.; Ariga, N.; Ito T. Copolymerization of methyl methacrylate. Makromol. Chem., 1966, 97, 128 -138.

[9] Paul, S.; Ranby, B. J. Polym. Sci. Polym. Chem. Ed., 1976, 14 2449.

[10] EL-Hamouly, S. H.; El-Shamy, W.; Aziz, E. H.; Abd-El Tour, K. $\mathrm{N}$. Ultrasonic detection of photo cross-linking in some acrylate copolymers. Polym. Degrad. Stab., 1992, 37(1), 41-49.

[11] Piracha, A.; Zulfiqar, S. The thermal degradation of glycidyl methacrylate-methyl methacrylate copolymers. Polym. Degrad. Stab., 1996, 51 (1), 27-34.

[12] Nita, L. E.; Chiriac, A. P. Possibilité d'obtention des copolymères à base de styrène et 2, 3-epoxy-propyl-methacrylate dans le champ magnétique, Proceedings at COFrRoCA, Slanic Moldova, Romania, 2004, 574 - 578.

[13] Nita, L.E.; Chiriac, A.P. A comparative study regarding the magnetic fields effect in the copolymer poly(styrene - co - 2,3epoxypropyl methacrylate). West University Annals, 2003, 42 (22), 19-23.

[14] Nita, L.E.; Chiriac, A.P. Polymerization in a magnetic field. 17. J. Appl. Polym. Sci, 2007, 104, 3029-3035.

[15] Porter, C. E.; Blum, F. D. Thermal characterization of PMMA Thin films using modulated differential scanning calorimetry. Macromolecules, 2000, 33, 7016-7020.

[16] Reich, L.; Levi, D.W. Thermal stability indices for polymeric materials based on energy considerations. Makromol. Chem., 1963, 66 , 102-104.

[17] Reich, L; Levi, DW Ed. Encyclopedia of polymer science end technology, New York: Interscienece Publishers, John Wiley and Sons, 1971, Vol 14, pp. 28

[18] Coats, A.W.; Redfern, J.P. Kinetic parameters from thermogravimetric data. Nature, 1964, 201, 68-69.

[19] Chiriac, A. P.; Simionescu, C.I. Magnetic field polymerisation. Prog. Polym. Sci., 2000, 25(2), 219-258.

[20] Chiriac, A. P. Polymerization in magnetic field. XVI. Kinetic aspects regarding methyl methacrylate polymerization in high magnetic field. J. Polym. Sci. Part A Polym. Chem., 2004, 42 (22), 5678-5686. 